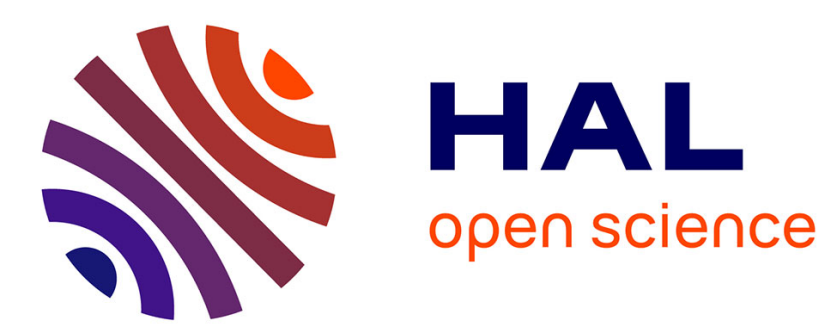

\title{
Interface changes causing accidents. An empirical study of negative transfer
}

Denis Besnard, Lucile Cacitti

\section{To cite this version:}

Denis Besnard, Lucile Cacitti. Interface changes causing accidents. An empirical study of negative transfer. International Journal of Human-Computer Studies, 2005, 62 (1), pp.105-125. 10.1016/j.ijhcs.2004.08.002 . hal-00549806

\section{HAL Id: hal-00549806 \\ https://hal-mines-paristech.archives-ouvertes.fr/hal-00549806}

Submitted on 22 Dec 2010

HAL is a multi-disciplinary open access archive for the deposit and dissemination of scientific research documents, whether they are published or not. The documents may come from teaching and research institutions in France or abroad, or from public or private research centers.
L'archive ouverte pluridisciplinaire HAL, est destinée au dépôt et à la diffusion de documents scientifiques de niveau recherche, publiés ou non, émanant des établissements d'enseignement et de recherche français ou étrangers, des laboratoires publics ou privés. 


\title{
INTERFACE CHANGES CAUSING ACCIDENTS. AN EMPIRICAL STUDY OF NEGATIVE TRANSFER
}

\author{
Denis BESNARD \\ School of Computing Science \\ University of Newcastle \\ Newcastle upon Tyne, NE1 7RU \\ UNITED KINGDOM \\ denis.besnard@ncl.ac.uk
}

\author{
Lucile CACITTI \\ Electricité de France \\ Département Facteurs Humains \\ 41220 Saint-Laurent des Eaux \\ FRANCE \\ lucile.cacitti@edf.fr
}

\begin{abstract}
When expert operators interact with a new device, they inevitably reuse former interaction modes and actions. This phenomenon is due to the human cognition seeking resources savings. Schemas support this strategy and are implemented in such a way that perfection is disregarded at the profit of an intuitive trade-off between performance and cognitive resources savings. As a consequence, humans have a strong inclination to fit well-known solution procedures into new problems. For this reason, changes in work environments can cause accidents when they allow operators to interact with a new device if the latter is erroneously perceived as familiar. This research issue originates from an industrial background. The suspected cause of a fatal error performed by an operator in a steelworks factory is replicated in an experiment. The results support the hypothesis according to which errors (and possible subsequent accidents) due to changes in the interface are more likely when the latter does not inhibit former modes of interaction. This main result is discussed under the angle of cognitive ergonomics and used as a basis to provide design guidelines.
\end{abstract}

Keywords: Negative transfer; Accident; Interface changes; Human-machine interaction; Human error.

\section{INTRODUCTION}

The study of field situations from the standpoint of cognitive ergonomics aims at understanding cognitive acts within the context in which they happen. Humans, their tools, their reasoning processes and actions inside the environment are classical features of this kind of approach. The latter can be deliberately quantitative when research aims at isolating a particular parameter, e.g. the cause of an error. In this case, experimentation can be used to assess the effect of one or several factors on a given aspect of behaviour. This is the direction taken in this paper. A field study was conducted in a steelworks company where an accident occurred, which led to the death of an operator. This study was initiated in order to trace back the psychological causes of this accident. The latter will be treated as an error in the humanmachine interaction.

We identify two wide classes of exception in human-machine interaction: a) exceptions that occur after deployment for which designers have not conceived any procedure due to the unlikelihood of these events and b) situations that are unexpectedly similar to others for which well-defined procedures and skills exist. Our paper deals with the second case and will try to highlight the risks associated with certain types of similarities at the interface level. The adopted angle sets the focus on the mental processes involved in interface changes. It follows that this paper is quite remote from raw performance metrics applied to interfaces (e.g. 
Rauterberg, 1992). Instead, an account of the mental processes involved in control tasks (as in Woods et al., 1987) and an analysis of the errors performed when interacting with changing interfaces will be presented.

\subsection{Description of the accident}

The following event occurred during a night shift in March 1990 at ASCOMETAL, a French steelworks factory employing some 500 people. An experienced operator was working on a thread drawing machine, a device that reduces the diameter of a metal thread by a series of tractions (see Figure 1). Typically, the output thread is coiled onto a drum and kept in place by pressing wheels. Opening and closing the wheels is done by rotating a two-positions button. Because of the high tension of the thread, there are times in the process where opening the pressing wheels is extremely hazardous.

The operator used to work with eleven thread drawing machines. On the machine involved in the accident, the open and closed positions of the pressing wheels button were swapped as compared to the ten other machines. This swap was well-known but was not flagged or equipped with any kind of protection. Because of the swapped commands, the operator unintentionally opened the pressing wheels at a step of the process where this action is forbidden. The operator was violently hit by the thread uncoiling from the drum. This resulted in the death of the operator.

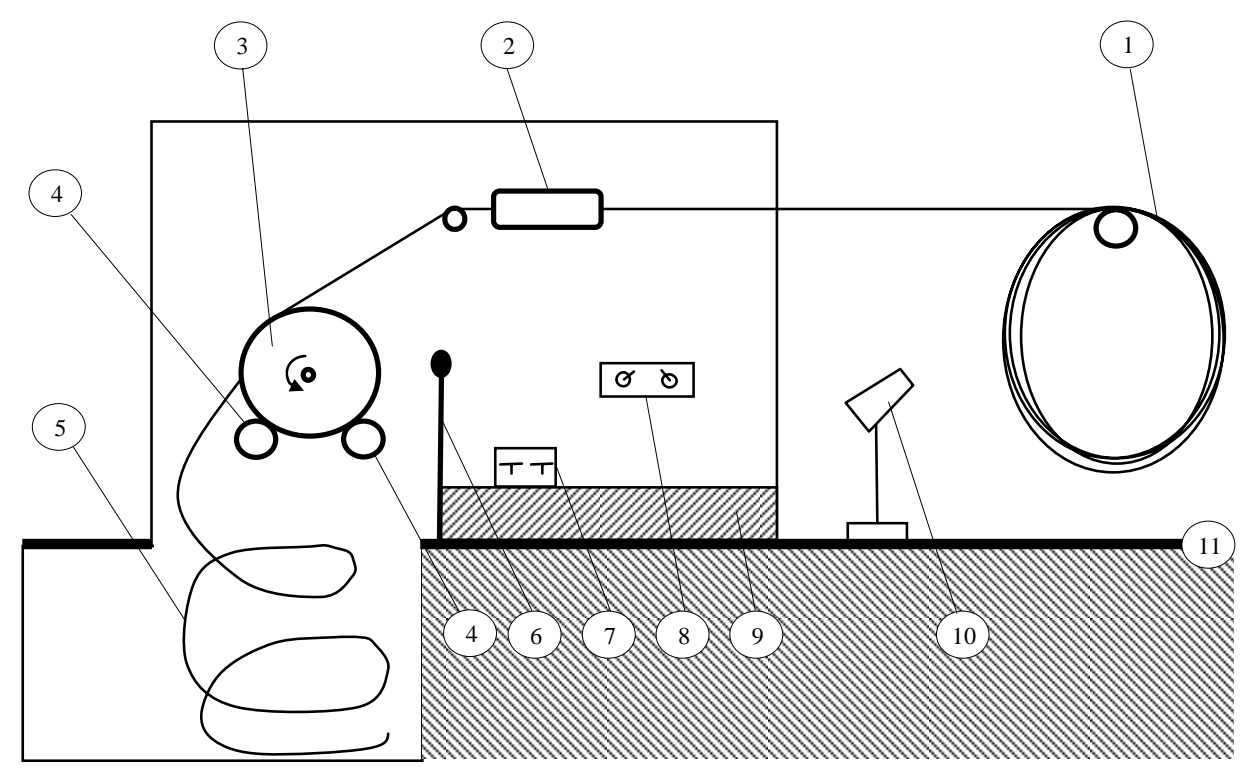

\begin{tabular}{ll}
\multicolumn{2}{c}{ Legends } \\
\hline 1- Input thread & 7- Coiling drum control pedals \\
2- Diameter reduction tool & 8- Pressing wheels control buttons \\
3- Coiling drum & 9- Operator's platform \\
4- Pressing wheel & 10- Main control panel \\
5- Output thread coiling in the pit & $11-$ Ground level \\
6- Safety barrier &
\end{tabular}

Figure 1: Schematic view of the cable drawing machine

From a psychological point of view, the tools' characteristics were discrepant with respect to the routine control mode. Therefore, the skills implemented by the operator did not match the specific constraints imposed by this tool. In other words, the accident did not occur because the operator simply made an error (see Doireau, Wioland \& Amalberti, 1995) but rather 
because the conditions in which this error occurred were unusual. When a tool changes, e.g. as the result of an upgrade, skills must adapt accordingly in order to reflect the changes and maintain the accuracy of the interaction. But updating skills requires repetitive feedback from the system in a wide variety of cases so that operators can progressively reduce the discrepancies between the system's expected behaviour and the system's actual behaviour. During this sensitive period, errors on critical functions of a hazardous tool can be fatal.

\subsection{Objective and outline of the paper}

Our objective is now to investigate, under laboratory settings, some of the factors that led to the accident. As Green and Hoc (1991) and Hoc (1993) suggest, this is a classic approach in cognitive ergonomics. Although it could be objected that lab experiments are far too reductive as compared to the complexity of natural environments (as noted by Perruchet, 1997), it nonetheless originates from a field situation, giving some credit to our approach (Sperandio, 1995). Also, laboratory experiments allow one to isolate a specific factor and to study it without unwanted contextual side-effects (work colleagues' conversation, unavailability of operators as experimental participants, managers supervising the operator during the experiment, etc.). Lastly, we believe even small-scale experiments are worth attempting. Since psychological data usually rely on a well-documented theoretical background, they still permit, however microscopic they are, to increase the predictive power of psychology. This approach is one where the human cognitive system is considered as a deterministic machine but whose complexity is still beyond our current predictive capacities.

The paper will mainly rely on a psychological theoretical framework in order to document the suspected core factors involved in the accident. We will test these factors in an experiment where we will assess the role of the mental processes involved. For scope matters, we will clearly disregard organisational factors, although we acknowledge they always play a significant role in accidents (see Bieder, 2000; Reason, 1990; 1995; 1997; 2000). In doing so, we will miss the richness of a multi-layered analysis. On the other hand, it will allow us to allocate more effort in an in-depth study of individual factors.

The outline of the paper is as follows. We will first present the cognitive concepts that framed the research (section 2). We will then describe the method of the experiment (section 3) designed to test the suspected causes of the accident. The results (section 4) will lead to a discussion on the theoretical and practical outcomes of our research (section 5).

\section{SCHEMA-DRIVEN COGNITION}

\subsection{Overview of the concept}

Schemas appear in a wide class of studies whose topics include medical diagnosis (Lesgold et al., 1988), car driving (Van Elslande, 1992), problem solving by analogy (Catrambone \& Holyoak, 1989; Novick \& Holyoak, 1991), aircraft piloting (Amalberti, 1992) and computer program understanding (Detienne, 1996). Schemas are high-level knowledge structures that support any aspect of knowledge and human skills (Reason, 1990). They support the fast processing of routine situations for which one acts virtually automatically from their identification. The concept of schema is close to Rasmussen's (1986) rule-based level of control and this parallel has already been established (Bollon \& Channouf, 1993) ${ }^{1}$. Historically, the concept of schema originates from Bartlett (1932) but some psychological

\footnotetext{
${ }^{1}$ Although schemas could be matched with the skill-based level of Rasmussen's (1986) model, we object that the latter is more about a sensorimotor level of control. We prefer the analogy to the rule-based level of control, following Salminen and Tallberg (1996).
} 
processes similar to schemas have been described, among others, by such terms as experiential knowledge (Fink \& Lusth, 1987), scripts (Boshuizen et al., 1991; Custers et al., 1996; Shank \& Abelson, 1977) and frames (Minsky, 1986). For the time being, let us just assert that a schema-based action is conditioned by the identification of a set of activators in a situation (e.g. the statement of a problem or the symptoms of an illness). These activators then trigger the schema which, in turn, controls the actions performed. The process is roughly similar to an [IF...THEN] statement where some conditions have to be detected for the schema to trigger (Govindaraj \& Su, 1988).

A schema is a piece of knowledge meant to solve problems for which skills have already been built. But since all problems are not familiar in the first place, we first need to have a look at a potential explanation for schema building. This will feed our description of the nature and role of schemas. When a problem is unknown ${ }^{2}$, one tries to solve it by trial and error, or formally speaking, by hypothesis testing (Byrne, 1989; Liu, 1991). Once a solution has been found, it usually can be stored in memory and thus becomes repeatable. With time, the repetitive exposure to the same category of problems leads to the building and recall of a generic solution. Also, trigger rules are progressively built, that bind together a) the solution and b) the category of problems it solves. On the basis of experience, this set of rules is progressively refined and tuned (Rauterberg, 1995) until it triggers the schema only for the relevant cases. However, because humans found their interaction with the world on memory of past experiences (Randel \& Pugh, 1996; Roediger, 1980), it happens that for most new problems, there is a solution to another problem that can be adapted for reuse. As we will see in the next section, this is a known feature of human cognition that can induce flaws in human-machine interaction.

\subsection{Schemas and negative transfer}

So far, schemas have been presented as a form of knowledge that supports human reasoning. As this research is interested in the cognitive features involved in the occurrence of an accident, the fallible aspect of human reasoning has to be addressed. We will thus revisit schemas under a very common angle in cognitive ergonomics: error. However, we have to emphasize that human errors are not always mere cognitive dysfunctions. Often, and it is the case in our study, errors are marginal events caused by the same mechanisms that generate correct acts most of the time (Johnson et al., 1992). As a consequence, errors are not byproducts of cognition. They are the side-effects of a risk induced by a heuristic reasoning strategy, the latter being aimed, time after time, at trading off an optimal performance against the lowest mental cost (Amalberti, 1996).

Since Simon (1957) and his concept of bounded rationality, it is accepted that humans' actions do not reach perfection. In this conception, humans' actions rather seek optimality with respect to their goals and what the cognitive resources allow. The fact that the cognitive system is not aimed at handling all the data available in the environment is a central aspect of the cognitive resources saving strategy. For instance, a general practitioner selects the symptoms that, by experience, have been discovered to be required for the diagnosis of given illness. Furthermore, these selected data do not all have the same status. The ones that support a core function of a task (or are typical of suspected illness) are often those which must be detected in priority. They happen to be stored in memory with functional alterations in order to increase their saliency in the environment and reflect their specific role (Endsley \& Smith, 1996; Ochanine, 1978; Moray, 1987). This view is part of a modern operational formalisation of reasoning activities where cognitive resources support the heuristic execution of a task rather than the exhaustiveness of a pure logical analysis.

\footnotetext{
2 e.g. the Hanoi tower, assuming one has never solved anything similar before.
} 
In line with the resources saving strategy, a schema provides a ready-made solution procedure in response to a situation identified as a pattern of data rather than as a series of hierarchical goals (see Boreham, Foster \& Mawer, 1992). However, one of the drawbacks of schemas (see Reason, 1987a for an overview) is that they can be activated as soon as their trigger conditions reach an appropriate level (Norman, 1983), even if these conditions are not optimal. Thus schemas can lead to errors when a known pattern of data is detected in an unknown problem. The latter can then be recognised as familiar, processed like a routine one with a high probability of errors. This explains why general practitioners sometimes have difficulties in identifying exceptional diseases and confuse their symptoms with more benign cases. Moreover, since expert operators usually allocate few resources for controlling the execution of a schema-driven action, they have difficulties in detecting exceptions. This phenomenon (experimentally studied by Bastien-Toniazzo, 1999 and Besnard, 2000) is a potential explanation for errors committed by expert operators.

The heuristic cognitive acts allowed by schemas aim at saving the resources allocated to the execution of a given task. One of the weaknesses of this saving strategy lies in the potentially flawed management of changing situations, which is the scope of this paper. For instance, when people lack knowledge on one aspect of a machine, they attempt to learn by analogy. This derivation may lead to errors if the mapping between one domain and the other is not consistent (Norman, 1983). Thus, when operators have developed skills on a given tool, changes in the interface may lead one to activate former control actions that have now become irrelevant. A negative transfer can then occur that impairs the performance on the task. As stated by Bösser (1983, p. 117), “... remindings often lead to ineffective and incorrect use of commands because analogies are based on irrelevant aspects of similarity of previous tasks". Bösser referred to studies performed in the domain of text editing when upgrading from a typewriter to a text-editor. In a similar domain, Walker and Olson (1988) demonstrated that keybindings that are built in a consistent manner (e.g. all deletions commands begin with the Alt key) limit interference effects when subsequent keybindings have to be learned. These authors define two directions of negative transfer: prospective and retrospective. Our study is interested in the former, where initial skills impair performance after a change. Readers can refer to Postman (1971) for a review of the various methods and experimental approaches to transfer.

Negative transfer can be a potential cause of accidents when this phenomenon happens in an environment where safety is a critical dimension. Johnson (1989) suggests that one needs to know a) what knowledge is likely to be transferred, b) what knowledge is appropriate or inappropriate to be transferred and c) what facilitates such a transfer. Our study will tackle these issues by investigating candidate conditions to negative transfer effects:

- Experience. The operator must be experienced since this transfer relies on a domainspecific (Schanteau, 1992) schema or rule-based level of control.

- Surface similarity. The previous interface must share specific features with the new interface for the latter to be identified as belonging to the area of expertise of the operator. These features are the ones the initial schema built itself upon and now needs to trigger.

- Structure discrepancy. The underlying structure of the task must have become discrepant to the surface features of the new interface.

In line with the accident described in section 1.1 and the theoretical background exposed in section 2, we expect errors to occur as a function of the similarity of mappings across interfaces. We know from the literature that if a schema can detect some activators belonging 
to a former interface, it is then likely that this schema will trigger and control the interaction with the new interface. Now, if discrepancies exist between the behaviour of the new interface and what the schema prescribes as correct actions, then errors have to be expected. This generic hypothesis will be tested on a simple simulated control task.

\section{METHOD}

\subsection{Description of the task}

We designed a simple computer-based control task (see screenshot in Figure 2). Participants have to fill up 4 classes of containers (upper left corner) with four classes of items (middle boxes).

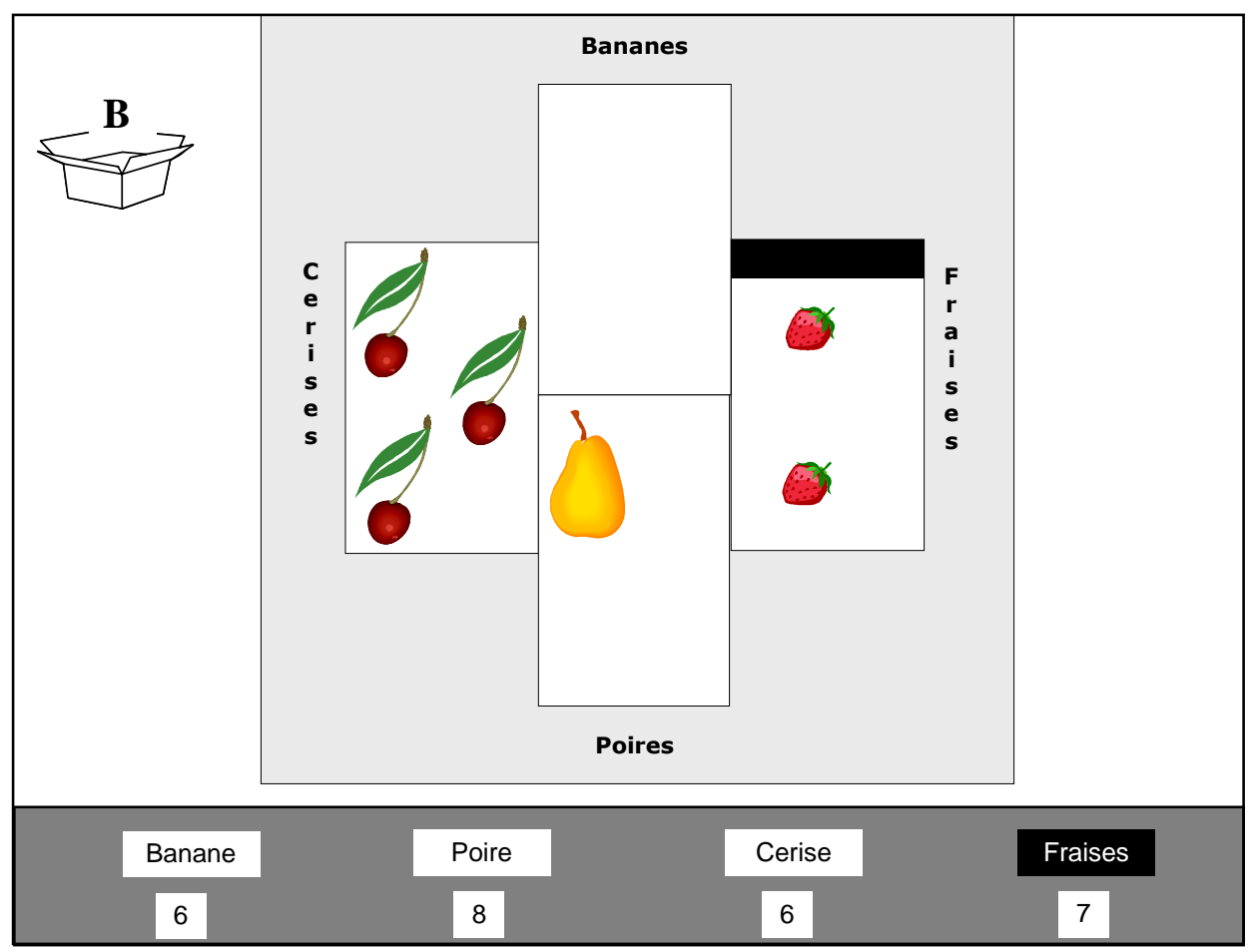

Figure 2: Screenshot of the interface of the control task

We chose to use fruits (bananas, pears, cherries and strawberries) for their ease of identification and intuitive meaning. The central area of the screenshot displays the four areas where the four classes of items are represented. The bottom count bar displays the number of items left to be processed.

The task can be described as picking up fruits and then putting them in a container when hands are full. It is cyclic and is composed of three stages.

- Step 1, Pointing. Participants ask the system to randomly point to a class of items. A black bar is then displayed on the top of the class box which the system points to.

- Step 2, Selecting. Participants have to respond by selecting the same class of items as the one pointed by the system. The class selected by participants is highlighted in the bottom count bar.

- Step 3, Filling or Emptying. Participants ask for one item of the selected class to be sent in the corresponding box. At this point, the cycle goes back to stage 1. When a box contains 3 items, participants must ask for it be emptied and a container appears on the screen. The cycle then goes back to step 1 (see Figure 3 below). 


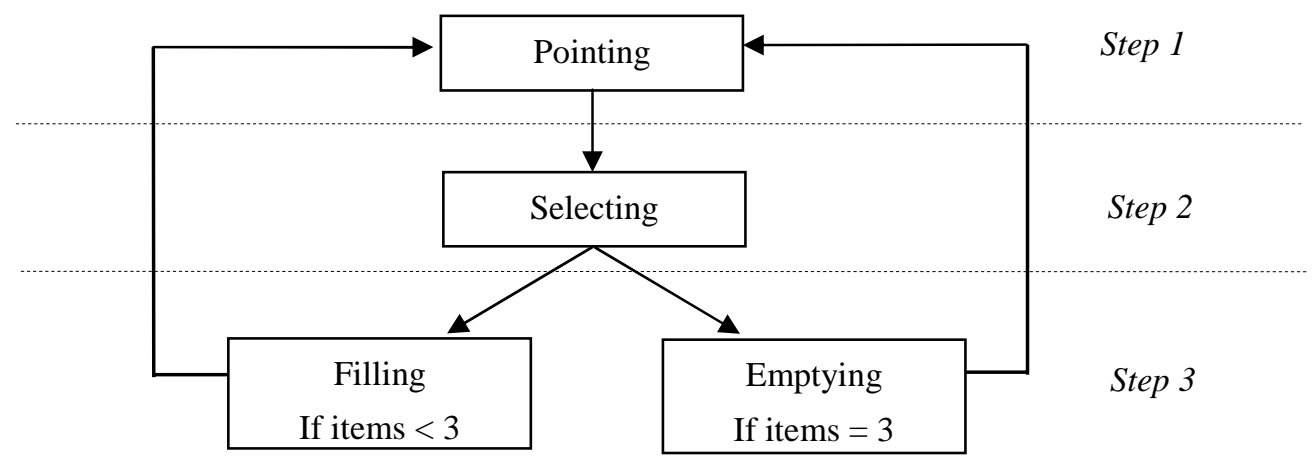

Figure 3: Description of a cycle

\subsection{Participants}

Twenty students, unselected for age and sex, from various departments of the University of Provence (France) took part in the experiment and were. Each group of 10 subjects was composed of 8 female and 2 male participants. Although differences in gender were balanced across groups, participants were left unscreened for age and background. Instead, we strictly controlled the level of performance of the participants in a training task (see section 3.3) before they were allocated to one or the other experimental condition (see section 3.4). The training task guaranteed that all participants had reached a performance baseline before they performed the experimental task. Despite the difference in the experimental and drawing machine tasks, if negative transfer can be observed among subjects that only have a few hours of practice, it may reveal the strength of the phenomenon among operators that have thousands of hours of experience in a highly specialised task.

\subsection{Training task}

The participants had to execute 108 cycles in 3 trials $^{3}$ without error, which set an even level of performance across the sample of participants. The task was restarted if an error occurred, until 108 error-free cycles were completed. The controls were keyboard-based according to Table 1 (upper section). The keys had colour stickers on so that participants could easily locate them on the keyboard. One participant did not reach the performance criterion and was not included in the rest of the study.

\subsection{Experimental conditions}

After the training session, the participants were assigned to one of the two following experimental conditions where they had another 108 cycles (still in 3 trials) to perform:

- Swapped commands. The controls were keyboard-based according to Table 1 (middle section);

- On-screen commands. The controls were icons displayed on the screen (see Figure 4 for a screenshot) and mapped to control functions as shown in Table 1 (lower section).

\footnotetext{
${ }^{3}$ The decomposition is as follows: 9 items per class $\mathrm{x} 4$ classes $\mathrm{x} 3$ trials.
} 
Table 1: Key-function mappings for the training phase, the swapped condition and the onscreen condition

\begin{tabular}{|l|c|c|c|c|}
\hline Key & \multirow{2}{*}{$\rightarrow$} & & \\
\hline Function & Pointing & Selecting & Filling & Emptying \\
\hline
\end{tabular}

Key-function mapping for the training phase

\begin{tabular}{|l|l|l|l|l|}
\hline Key & $\rightarrow$ & & \\
\hline Function & Pointing & Selecting & Filling & Emptying \\
\hline
\end{tabular}

Key-function mapping for the swapped condition

\begin{tabular}{|l|c|c|c|c|}
\hline Icon & \multirow{2}{*}{} & & \\
\hline Function & Pointing & Selecting & Filling & Emptying \\
\hline
\end{tabular}

Key-function mapping for the on-screen condition

In each condition, an on-screen message was displayed when a participant made an error. This had no consequence over the performing of the task.

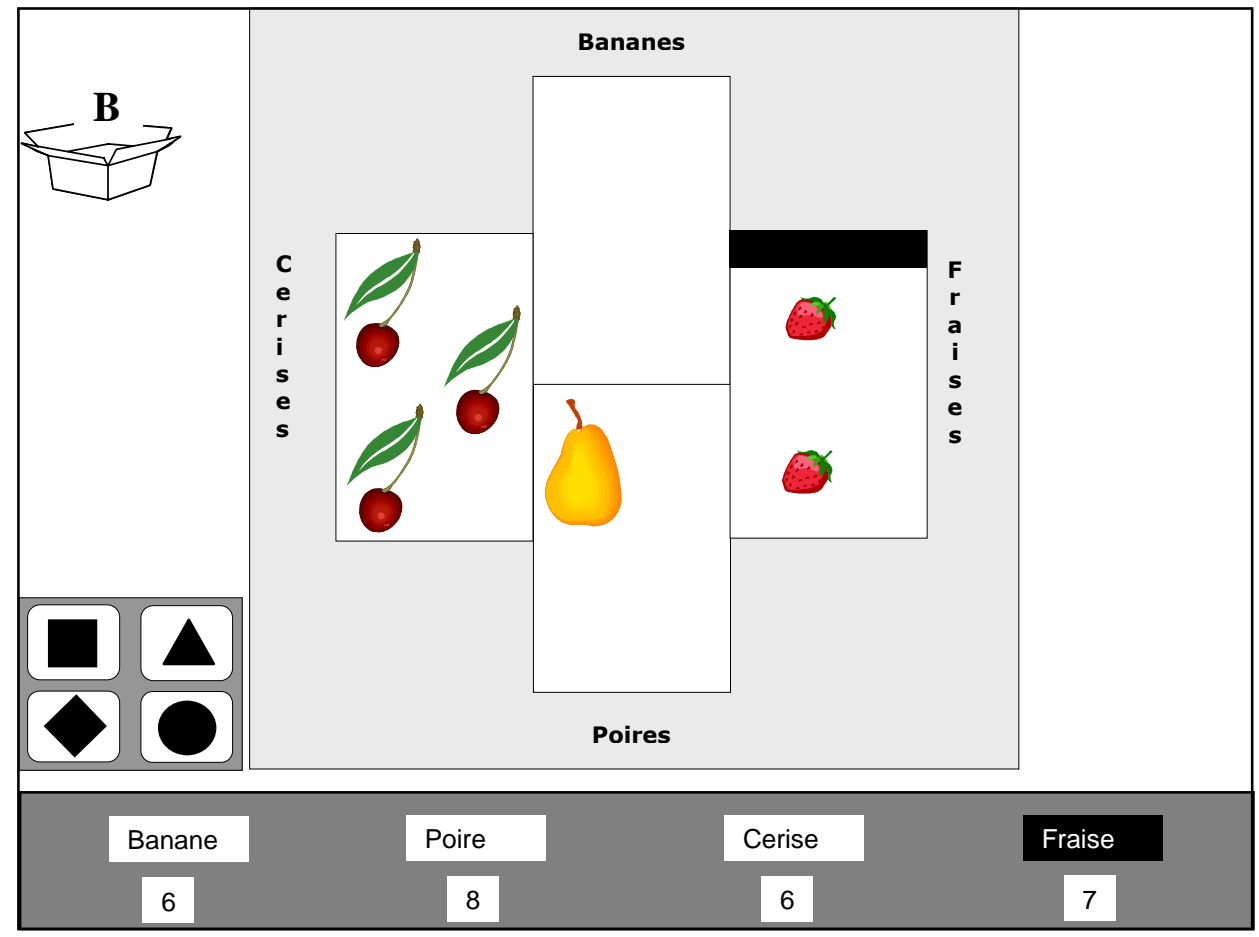

Figure 4: Screenshot of the interface for the on-screen condition

Needless to say, the splitting of experimental conditions into two discrete categories does not reflect the spectrum of similarity that exists in real work conditions. Namely, interfaces can be more or less similar to one another, as opposed to merely similar or different. The idea of a 
break point in the abovementioned spectrum might account better for the distribution of performance levels. However, this angle requires an experiment of a wider scale than the one reported here since a large number of conditions have to be tested. For the sake of clarity, we therefore opted for a simple experimental plan which we believe is adapted to the simple question we ask in this research.

\subsection{Variables}

The participants performed 3 trials from which the means of the following dependent variables were formed ${ }^{4}$ :

- Time. This is the number of seconds needed by the participants to complete the task.

- Total. This is the mean of all the other variables below. Because it is a mean, its value is lower than that of some of the variables.

- Omission errors. They are one or several steps that are skipped in a cycle.

- Commission errors. They are actions that are not relevant to the current system's state. It is the case of a participant who would empty a class box before it is full (i.e. it contains less than 3 items).

- Previous interface. These errors would have been correct actions under the training interface. This is an essential variable for our analysis of the negative transfer.

- Other errors. These are erroneous actions such as mistyping or any other action that cannot be interpreted as belonging to the above variables.

\subsection{Predictions}

We assume that errors will originate from the failure to inhibit key-function mappings built during the training phase. When the interface changes, we expect interferences to occur due to the persistence of these previous mappings. As our aim is to experimentally investigate negative transfer rather than decomposing it into its sub-components, we do not make predictions for each variable. We will only expect the following:

- In the swapped condition, we globally expect a large number of errors since the same keyboard keys are now dedicated to different functions. The similarity with the keyfunction mapping of the training phase should leave enough room for the former schema to partly override the learning of the new interface. This may cause major disruptions in participants' performance and it is the condition where errors due to the previous interface (the training one) are expected to be highest.

- In the on-screen condition, the very nature of the interface will have changes. The participants will control the system via a mouse by clicking on icons displayed on the screen (see screenshot in Figure 4). Because of the difference with the training interface, we predict that this experimental condition restricts the possibilities of transferring the previous key-function mapping. As a consequence, we expect less disruptions in this condition. Additionally, we expect the errors due to the previous interface to be lowest in this condition.

\section{RESULTS}

The significant results are summarised in Table 2 and in Figure 5. Comments will appear in the next section.

\footnotetext{
${ }^{4}$ The variables labelled omission errors and commission errors are derived from Gobet \& Simon (1996) and Hollnagel (1993).
} 
Table 2: Summary of the significant means. Minimum and maximum scores appear as raw, individual data. These scores in the total column are not the sum of the scores on the other variables.

\begin{tabular}{|c|c|c|c|c|c|}
\hline & total & omission & commission & prev. interface & other \\
\hline On-screen & 0.3 & 0.03 & 0.23 & 0.19 & 0.09 \\
\hline min. score & 0 & 0 & 0 & 0 & 0 \\
\hline max. score & 3 & 1 & 1 & 2 & 2 \\
\hline$S D$ & 0.33 & 0.10 & 0.22 & 0.23 & 0.22 \\
\hline Swapped & 1.8 & 1.2 & 0.57 & 0.89 & 0.89 \\
\hline min. score & 2 & 0 & 0 & 0 & 1 \\
\hline max. score & 15 & 13 & 4 & 6 & 9 \\
\hline$S D$ & 1.29 & 1.98 & 0.47 & 0.63 & 0.89 \\
\hline F value & 12.54 & 9.40 & 4.05 & 10.87 & 7.6 \\
\hline df & 18 & 18 & 18 & 18 & 18 \\
\hline $\mathrm{p}$ & 0.002 & 0.006 & 0.059 & 0.004 & 0.013 \\
\hline
\end{tabular}

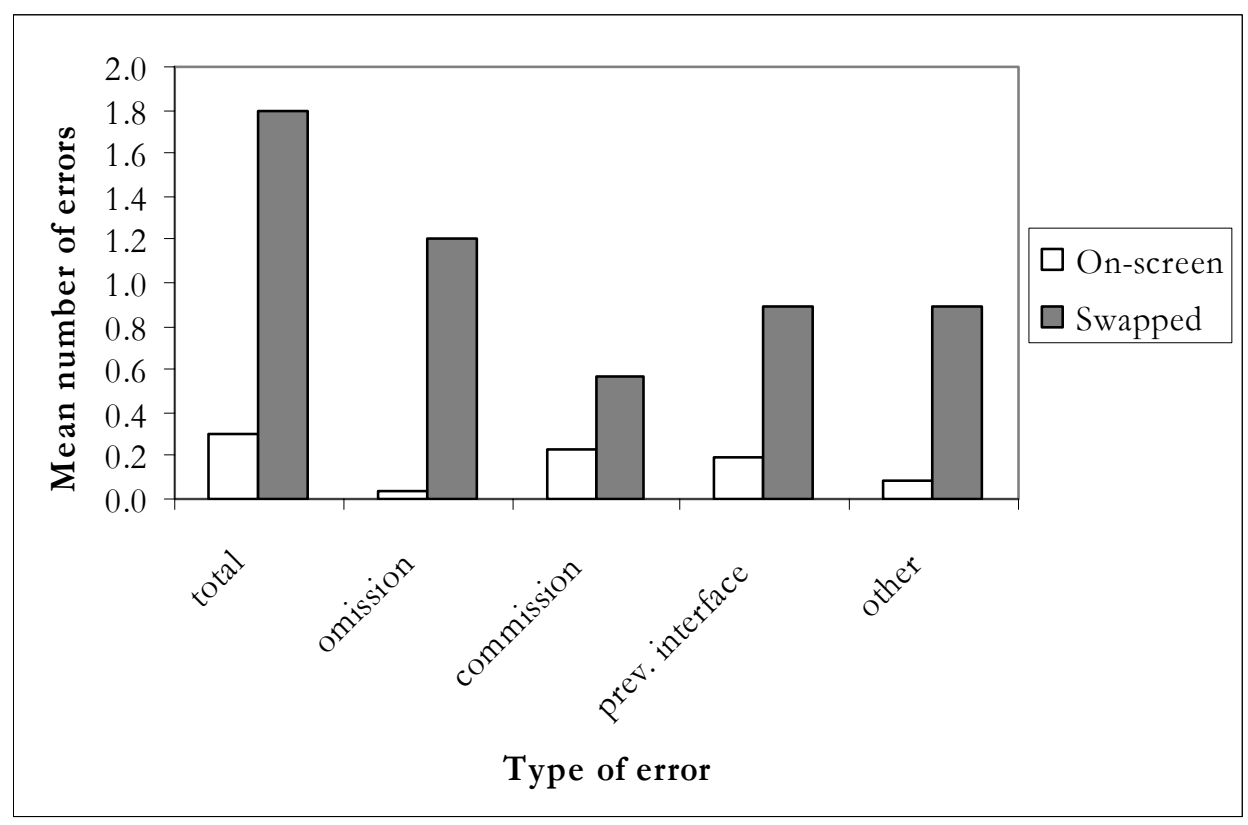

Figure 5: Graphical representation of the significant means

An analysis of variance at a significance threshold of .05 revealed the following results. The effect of interface on time did not reach significance (on screen $=220.26$; swapped $=216.66$; $\mathrm{F}(1 ; 18)=0.02 ; p=.885)$. The effect of interface on the mean total number of errors did reach significance: In the on-screen condition, participants performed a mean of 0.3 errors vs. 1.8 in the swapped condition $(\mathrm{F}(1 ; 18)=12.54 ; p=.002)$. Three out of five of the error measures (omission, commission \& previous interface, respectively) reached significance. The details of these three results now follow.

Firstly, the number of omission errors differed significantly across groups. In the on-screen condition, participants performed 0.03 errors $v s .1 .2$ in the swapped condition $(\mathrm{F}(1 ; 18)=9.40$; $p=.006)$. Secondly, the effect of interface on commission errors produced marginally significant differences. The on-screen participants performed 0.23 error vs. 0.57 for the swapped participants $(\mathrm{F}(1 ; 18)=4.05 ; p=.059)$. Thirdly, as predicted, there were fewer errors 
due to the previous interface in the on-screen condition $(\mathrm{m}=0.19)$ than in the swapped condition $(\mathrm{m}=0.89)(\mathrm{F}(1 ; 18)=10.87 ; p=.004)$.

Similarly to the above, the effects of the interface change on the other errors were lower in the on-screen condition $(\mathrm{m}=0.09)$ than in the swapped condition $(\mathrm{m}=0.89 ; \mathrm{F}(1 ; 18)=7.60 ; p=.013)$.

As stated in section 3, participants all had to perform 3 trials during both the training and the experimental task. While the data for the training phase were not available, we nonetheless carried out a simple descriptive analysis of the decay of the number of errors over trials in the experimental conditions (on-screen vs. swapped). Table 3 and Figure 6 provide a summary of the data.

Table 3: Mean number of errors over trials

\begin{tabular}{l|ccc} 
& trial 1 & trial 2 & trial 3 \\
\hline On-screen & 0.7 & 0 & 0.2 \\
\hline Swapped & 2.3 & 1.8 & 1.3 \\
\hline
\end{tabular}

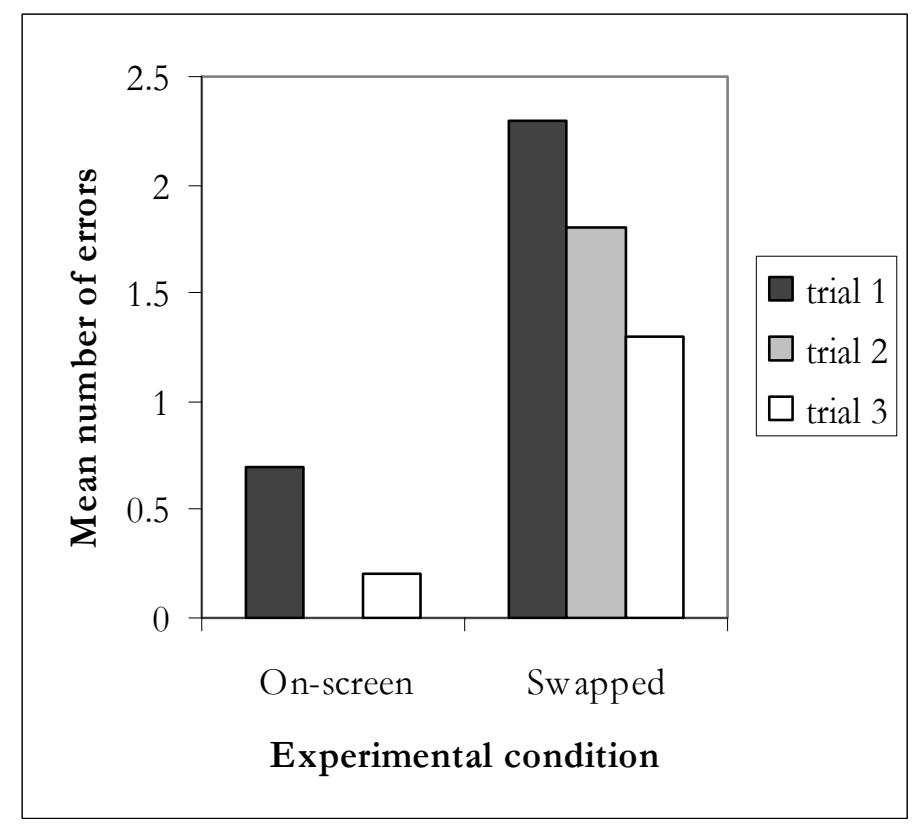

Figure 6: Graphical representation of the mean number of errors over trials

Although no statistical analysis of the local effects of each trial has been carried out, the data seem to suggest that a) the mean total number of errors was globally decreasing over trials in all conditions and $b$ ) this decrease started from a much lower error score in the on-screen condition. This might explain why the total number of errors in this latter condition is significantly lower than in the swapped condition (see Table 2).

\section{DISCUSSION}

As we have seen in the previous section, all significant error measures show higher values in the swapped condition. This is the interface where the negative transfer effect is strongest and causes major disruptions in performance. Considering this in more detail, the results show that omission errors are more contrasted across the two conditions than commission errors, 
the latter reaching a poor level of statistical significance $(p=.059)$. The errors due to the previous interface show a significant difference between the two conditions. Again, the swapped condition shows the highest number of errors. The other errors also show a higher rate in the swapped condition, conforming to the trend of results. In a future work, it would be worth splitting this variable and investigating it more deeply as it may reveal some nuances that our generic, high-level variables have probably masked. In our interpretation, the swapped interface causing more errors than the screen interface is due to the activation of a former schema. Thus, as a preliminary conclusion, it seems highly plausible that a negative transfer occurs when two interfaces or problems share surface features but have different structures (Blessing \& Ross, 1996; Novick, 1988).

In hindsight, the changes we have implemented in our experiment can be seen as dramatic ones. From a human-machine interaction point of view, the swapped condition has a massively disruptive impact on the interaction. It allocates previous commands to new functions and, as demonstrated by the experiment, this is the worst change one could ever think of. However, these changes are not that radical from a design point of view. The commands and the functions in the swapped condition are still the same as in the training phase, as opposed to the on-screen condition. So one issue here is that the effect of changes on performance cannot be directly derived from the amount of graphical amendments to the interface. Instead, a dimension of importance is the extent to which the changes performed still allow the operator to erroneously activate pre-existing skills, given that some transfer will inevitably occur.

\subsection{A heuristics-based interpretation}

Reason (1990) and Decortis (1993) suggest that the human reasoning globally obeys two heuristics: frequency gambling and similarity matching. Our research is clearly concerned with these concepts. We suspect that when a novel interface shares features with a previous one, action patterns that relied on these features in the past tend to be imported and potentially abusively reused. This cognitive resource-saving strategy is heuristic since it tolerates imperfection. We are of the opinion that this constitutes the cognitive cause of negative transfer. Figure 7 provides a graphical description of this mechanism.

The building of negative transfer across the computer interfaces is described in the left-hand side of the figure whereas the right-hand side is about the drawing machine interfaces. These two devices seem to each provide an instance of the abovementioned similarity matching and frequency gambling heuristics, respectively. From this standpoint, the similarity between the training interface and the swapped interface caused an expert mapping to persist across conditions. In the case of the drawing machine interface, we are of the opinion that the steelworks operator rather relied on a frequency gambling, due to the particular accidental machine's interface standing alone in a group of eight other uniform machines. Possible contributing factors to negative transfer might be workload, fatigue, lack of vigilance and other performance shaping factors (as described in Miller \& Swain, 1987). These external constraints, combined with the cognitive resources saving strategy that underlies the interaction economy, can cause changes to be overlooked thereby letting the most frequent routine take over the choice of actions. 

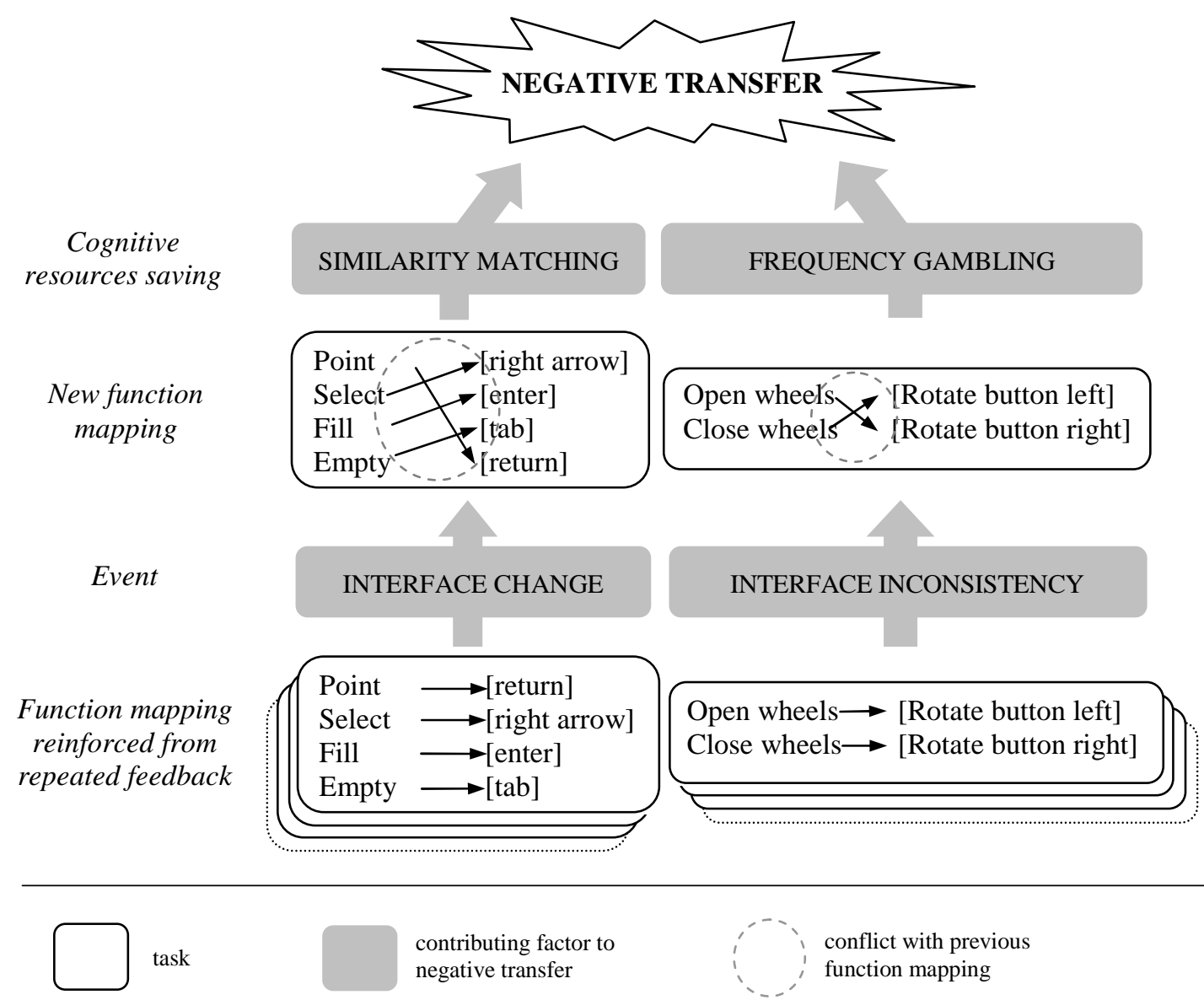

Figure 7: Descriptive model of the negative transfer mechanism

It now has to be said that the heuristic interaction mode that humans adopt in their daily activities usually provides a high level of performance. Human cognition is indeed extremely good at modelling the regularities of the past, storing and reusing them as a basis for some automatic control of actions (Reason, 1987b). This strategy only fails under exceptional circumstances. Therefore, we must make clear that a heuristic is not an error generator per se.

\subsection{Rigidity of expert knowledge}

Expert operators can cross the boundaries of their expertise without awareness. In the accident described in section 1.1, the operator had overlooked an exception at his workplace and implemented routine actions under misdetected non-standard settings. It is already known that the more expert operators are, the more rigid (i.e. less adaptable) their knowledge tends to be (Gaba, 1991; Hollnagel, 1987; Moray, 1987; Rasmussen \& Jensen, 1974). Also, as Reason (1987a) puts it, schema-based reasoning is rigid and rule-bound. Solutions to previous problems can thus be applied with little attention paid to changes. Rigidity is a drawback especially in new situations. It may lead to poor adaptability because of the schema-driven (or rule-based) interaction mode being highly prevalent upon any other. It can be noted from Figure 6 that the differences in the strength of negative transfer (as described by the differences in the mean number of errors over trials) seem to be due to the absolute value from which participants start to adjust to the new interface. In this respect, the effects of negative transfer could be caused by the difficulty of unlearning previous knowledge and inhibiting previous automatisms. This may explain why participants who have to learn a new, different key-function mapping (the on-screen condition) show a better performance level. In 
this respect, the data gathered about the accident and the results obtained in the experiment are pieces of evidence of the potential fallibility of cognitive resource-saving strategies across changing environments.

\subsection{Methodological considerations}

We demonstrated that some components of expertise can be transferred across interfaces out of any control from the operator. It can nonetheless be objected that our experiment compares participants and tools that differ very much from the original industrial situation (see Karnas \& Van De Leemput, 1990). At first sight, this seems undeniable but it does not mean that there is nothing to be learned. The objective of our study was to isolate what we believe is a task-independent error mechanism and quantify its effects on a control task. We hope we have demonstrated that the hypothesized causes of the negative transfer in the experiment could shed some light on the causes of the accident with the thread drawing machine. In our opinion, the accident and the experiment shared features that allowed us to test the hypothesis of negative transfer as a cause of error in the cognitive processing of changing interfaces. As summarised by Figure 7, errors in different work settings can be accounted for by similar mechanisms. But this may be how far we can stretch the comparison between our experiment and the accident. The testing of another hypothesis (e.g. fatigue, light conditions, etc.) would most likely require a totally different experiment.

The complexity of natural work places cannot be cheaply replicated by computer simulations. However, a single variable of this complexity (e.g. a suspected error mechanism) can be isolated and brought into the laboratory. For such a study, all that is needed is an experimental environment that allows one to manipulate the relevant variables (as suggested by Diaper, 1989). Surface similarities between the natural task and the simulated one are therefore not mandatory. As always, the drawback in such an approach is the loss of the interaction between the variable under study and the environment of the natural task. This is nothing but a dilemma since the taking into account of the whole complexity of natural environments does not allow any clear understanding of isolated variables.

\subsection{Recommendations}

We must not assume that humans, especially operators in hazardous processes, always have an opportunity for learning. They sometimes die from their errors. Therefore, some psychology-centred guidelines may be needed by designers who have to deal with changes in evolving interfaces. Hopefully, some of the inherent fallibility of the human cognitive processes can be cheaply handled within the design process instead of being dealt with retrospectively, at the cost of safety.

The accidental situation we have analysed in this research was similar enough from routine ones for it to trigger a skill-based pattern of action (see Rasmussen, 1986). From an interdisciplinary point of view, it seems to the authors that whatever could help in gaining some soundness in design principles is worth spending some effort. From the parallels we drew between our industrial case and the experiment, we will now introduce some simple recommendations to interface designers in charge of systems ranging from industrial machines' interfaces to computer-based control tasks' interfaces. These recommendations assume that a) a high performance level on the part of operators and b) the resulting reliability of the interaction, require the mental processes involved in human-machine interaction to be taken into account when designing work stations (Woods et al., 1987).

- Warnings are not enough. When a change has to be accommodated for by the operators of critical tools, warnings are only a starting point. In the end, they help very 
little since declarative knowledge (e.g. "I have been told that this tool is different than the others") is not strongly correlated to the level of performance (Schraagen \& Schaafstal, 1996). For instance, the participants of our experiment were told that a change had occurred between the training condition and the experimental condition. However, the results show clearly that it was not enough for their performance to reach the same level as with the previous interface.

- Don't change the interface. Heuristics can cause accidents when they drive the interaction on interfaces that have changed since it can make these changes easy to overlook. This is a serious issue in critical environments. So we suggest that where the rules underlying the interaction are kept unchanged (e.g. during an upgrade), the command-function mappings should be kept unchanged. Namely in the case of a changed interface, new critical functions should not be triggered by pre-existing commands. Equally, pre-existing critical functions should not be given new commands. However, it has to be acknowledged that systems evolve and function mappings cannot always be kept unchanged. Designers should then consider the next recommendation.

- Too much is better than too little. Under the conditions that we have studied, mapping changes in an interface can impact on the interaction more than a totally different design option. The difficulty of unlearning previous knowledge suggests that whenever an interface change is performed and there is a change in the commandfunction mapping, the new interface should share as few features as possible with the former interface.

- Keep things consistent. As stated many years ago by Maas (1983), consistency in interfaces is one of the keys to system's transparency. Operators show highest levels of performance when the same commands are linked to the same functions. From this perspective, it seems obvious that the interface discrepancy of the accidental machine with respect to the eight others was a strong contributing factor to the death of the operator. When consistency cannot be achieved (e.g. for cost reasons), designers should consider the next recommendation.

- Implement enabling actions. Operators may disregard such things as warning notices and signals because of factors like stress or lack of vigilance. Therefore, as a complement, a safety device (see Etherton, 1987, for a review) can be required from operators before they can use a given function. In the industrial case depicted in section 1.1, this device could take the form of an enabling action such as the removal of a safety cap fitted to the pressing wheels button before using the machine. The idea here is to insert a break point in a routine plan and therefore force the acknowledgement of the exceptional nature of the device settings. It also temporarily introduces a higher level of cognitive control, thereby easing the rejection of planned actions assessed as irrelevant.

\section{LIMITS}

There is a number of related issues that have not been addressed in this paper. One is the mode confusion angle (Crow et al., 2000; Leveson et al., 1997) that describes how correct actions in particular settings happen to be incorrect in others. We did not mention either such factors as decay of vigilance (the accident occurred during a night shift) or slips which are known to contribute significantly to occupational accidents. Last but not least, some management considerations that have not been included here could help in understanding the mechanism that led to neglect interface issues in such a hazardous environment as steelworks. 


\section{CONCLUSION}

In this paper, we attempted to understand and assess in an experiment, the psychological causes of an accident that occurred in a steelworks factory, causing the death of an operator. Among other factors that we briefly list in section 6, this fatality was caused by changes at the workplace not being taken into account by the operator during routine actions. In our opinion, a negative transfer caused these familiar operations to trigger within work settings where they no longer were relevant. The results of the experiment supported this hypothesis. Changes in the interface of a simulated control task generated a negative transfer, causing errors due to well-known actions being called under new settings. From the accident data, the results of the experiments and the theoretical background, we concluded that human cognition fallibility accounts for some of the errors performed during changes in work settings. However, this does not mean that this state of facts has to be passively accepted. Instead, we formulate simple yet design-centred comments considering human cognition with regards to hazardous systems design. Lastly, following Hollnagel (1993), we think the systematic study of erroneous actions has the potential to provide a better knowledge of human failure modes and to influence the design of more reliable systems. This paper represents our contribution to this research avenue.

\section{REFERENCES}

Amalberti, R., 1992. Safety and process control: An operator centred point of view. Reliability Engineering and System Safety, 38, 99-108.

Amalberti, R., 1996. La conduite de systèmes à risques (The conducting of hazardous systems). Paris, Presses Universitaires de France.

Bartlett, F C., 1932. Remembering: An Experimental and Social Study. Cambridge, Cambridge University Press.

Besnard, D. \& Bastien-Toniazzo, M., 1999. Expert error in trouble-shooting. An exploratory study in electronics. International Journal of Human-Computer Studies, 50, 391-405.

Besnard, D., 2000. Expert error. The case of trouble-shooting in electronics. Proceedings of the 19th international conference SafeComp 2000, Rotterdam, Netherlands (pp. 74-85).

Bieder, C., 2000. Comments on the JCO accident. Cognition, Technology \& Work, 2, 204-205.

Blessing, S. B. \& Ross, B. H., 1996. Content effects in categorization and problem solving. Journal of Experimental Psychology: Learning, Memory and Cognition, 22, 792-810.

Bollon, T. \& Channouf, A., 1993. Travail sur machine-outil et activité de planification (Work on machine-tool and activity of planning). In Proceedings of Recherches pour l'Ergonomie. University of Toulouse-le-Mirail, France.

Boreham, N. C., Foster, R. W. \& Mawer, G. E., 1992. Strategies and knowledge in the control of a chronic illness. Le Travail Humain, 55, 15-34.

Boshuizen, H. P. A., Hobus, P. P. M., Custers, E. J. F. M. \& Schmidt, H. G., 1991. Cognitive effects of practical experience. In D. A. Evans \& V. L. Patel (Eds) Advanced models of cognition for medical training and practice. Heidelberg, Springer Verlag. (pp. 337348).

Bösser, T., 1983. Learning in man-computer interaction. Springer-Verlag, Berlin.

Byrne, R. M. J., 1989. Human deductive reasoning. The Irish Journal of Psychology, 10, 216231. 
Catrambone, R. \& Holyoak, K. J., 1989. Overcoming contextual limitations on problemsolving transfer. Journal of Experimental Psychology: Learning, Memory and Cognition, 15, 1147-1156.

Crow, J., Javaux, D. \& Rushby, J., 2000. Models and mechanized methods that integrate human factors into automated design. Proceedings of the International Conference on human-computer interaction in aeronautics: HCI-Aero 2000, Toulouse, France, September 2000.

Custers, E. J. F., Boshuizen, H. P. A. \& Schmidt, H. G., 1996. The influence of medical expertise, case typicality and illness script component on case processing and disease probability estimates. Memory and Cognition, 24, 384-399.

Decortis, F., 1993. Operator strategies in a dynamic environment in relation to an operator model. Ergonomics, 36, 1291-1304.

Detienne, F., 1996. What models for program understanding? Actes du colloque Using Complex Information. University of Poitiers, France (pp. 60-66).

Diaper, D., 1989. Task observation for human-computer interaction. In D. Diaper (Ed.) Task analysis for human-computer inetraction. Chichester, Ellis Horwood (pp. 210-251).

Doireau, P., Wioland, L. \& Amalberti, R., 1995. La détection de l'erreur par un tiers en situation de pilotage d'avions (Error detection by a third-party in aircraft piloting). Service de Santé des Armées. Travaux Scientifiques, 16, 291-292.

Endsley, M. \& Smith, R. P., 1996. Attention and decision making in tactical air combat. Human Factors, 38, 232-249.

Etherton, J. R., 1987. The use of safety devices and safety controls at industrial machine work stations. In G. Salvendy (Ed.) Handbook of Human Factors, New York, John Wiley \& Sons (pp. 861-875).

Fink, P. K. \& Lusth, J. C., 1987. Expert systems and diagnostic expertise in the mechanical and electrical domains. IEEE Transactions on Systems, Man and Cybernetics, 17, 340349 .

Gaba, D., 1991. Dynamic decision making in anesthesiology: Cognitive models and training approaches. In D. A. Evans \& V. L. Patel (Eds) Advanced models of cognition for medical training and practice. Heidelberg, Springer Verlag (pp. 123-147).

Gobet, F. \& Simon, H. A., 1996. Templates in chess memory: A mechanism for recalling several boards. Cognitive Psychology, 31, 1-40.

Govindaraj, T. \& Su, Y. D., 1988. A model of fault diagnosis performance of expert marine engineers. International Journal of Man-Machine Studies, 29, 1-20.

Green, T. R. G. \& Hoc, J. M., 1991. What is cognitive Ergonomics? Le Travail Humain, 54, 291-304.

Hoc, J.-M., 1993. Conditions méthodologiques d'une recherche fondamentale en psychologie ergonomique et validité des résultats (Methodological conditions for basic research in ergonomic psychology and validity of results). Le Travail Humain, 56, 171-184.

Hollnagel, E., 1987. Information and reasoning in intelligent decision support systems. International Journal of Man-Machine Studies, 27, 665-678.

Hollnagel, E., 1993. The phenotype of erroneous actions. International Journal of ManMachine Studies, 39, 1-32. 
Johnson, P. E., Grazioli, S., Jamal, K. \& Zualkernan, I. A., 1992. Success and failure in expert reasoning. Organisational Behavior and Human Decision Processes, 53, 173-203.

Johnson, P., 1989. Supporting system design by analysing current task knowledge. In D. Diaper (Ed.) Task analysis for human-computer inetraction. Chichester, Ellis Horwood (pp. 160-251).

Karnas, G. \& Van De Leemput C., 1990. L'ergonomie de conception du dialogue hommeordinateur. Généralité et relativité des résultats (The ergonomics of the design of manmachine dialog. Generality and relativity of results). Le Travail Humain, 53, 303-311.

Lesgold, A., Glaser, R., Rubinson, H., Klopfer, D., Feltovitch, P. \& Wang, Y., 1988. In M. T. H. Chi, R. Glaser \& M. J. Farr The nature of expertise. Hillsdale, NJ, Lawrence Erlbaum (pp. 310-342).

Leveson, N., Pinnel, L. D., Sandys, S. D., Koga, S. \& Reese. J. D., 1997. Analysing software specifications for mode confusion potential. In C. W. Johnson (Ed.) Proceedings of a workshop on human error and system development. Glasgow, Scotland (pp. 132-146).

Liu, X., 1991. Hypotheses testing by fundamental knowledge. International Journal of ManMachine Studies, 35, 409-427.

Maas, S., 1983. Why systems transparency? In T. R. G. Green, S. J. Payne \& G. C. Van Der Veer (Eds.) The psychology of computer use, London, Academic Press (pp. 19-28).

Miller, D. P. \& Swain, A. D., 1987. Human error and human reliability. In G. Salvendy (Ed.) Handbook oh Human Factors, New York, John Wiley \& Sons (pp. 219-250).

Minsky, M., 1986. The Society of Mind. New York, Simon \& Schuster.

Moray, N., 1987. Intelligent aids, mental models, and the theory of machines. International Journal of Man-Machine Studies, 27, 619-629.

Norman, D., 1983. Design rules based on analyses of human error. Communications of the $A C M, 26,254-258$.

Novick, L. R., 1988. Analogical transfer, problem similarity, and expertise. Journal of Experimental Psychology: Learning, Memory and Cognition, 14, 510-520.

Novick, L. R. \& Holyoack, K. J., 1991. Mathematical problem solving by analogy. Journal of Experimental Psychology: Learning, Memory and Cognition, 17, 338-415.

Ochanine, D., 1978. Le rôle des images opératives dans la régulation des activités de travail (Role of operative images in the regulation of work activities). Psychologie et Education, 2, 63-72.

Perruchet, P., 1997. Le rôle de l'attention dans les apprentissages implicites (Role of attention in implicit learning). In Mellier, D., Von Hofe, A. Attention et contrôle cognitif. Rouen, Presses Universitaires de Rouen (pp. 19-27).

Postman, L., 1971. Transfer, interference and forgetting. In J. W. Kling \& L. A. Riggs (Eds.) Woodworth and Schlosberg's experimental psychology. New York, Holt, Reinhart \& Winston (pp. 1019-1132).

Randel, J. M. \& Pugh, H. L., 1996. Differences in expert and novice situation awareness in naturalistic decision making. International Journal of Human-Computer Studies, 45, $579-587$.

Rasmussen, J. \& Jensen, A., 1974. Mental procedures in real life tasks. A case study in electronics trouble shooting. Ergonomics, 17, 293-307. 
Rasmussen, J., 1986. Information processing and human-machine interaction. North Holland: Elsevier Science.

Rauterberg, M., 1992. An emprical comparison of menu-selection (CUI) and desktop (GUI) computer programs carried out by beginners and experts. Behaviour and Information Technology, 11, 227-236.

Rauterberg, M., 1995. About faults, errors and other dangerous things. In H. Stassen \& P. Wieringa (Eds.) Proceedings of the XIV European annual conference on human decision making and manual control, Delft University of Technology (session 3-4, pp. $1-7)$.

Reason, J., 1987a. A preliminary classification of mistakes. In J. Rasmussen, K. Duncan \& J. Leplat (Eds.) New technology and human error. Chichester, UK, Wiley \& Sons Ltd.

Reason. J., 1987b. Cognitive aids in process environments: Prostheses or tools? International Journal of Man-Machine Studies, 27, 463-470.

Reason, J., 1990. Human error. Cambridge: Cambridge University Press.

Reason, J., 1995. A systems approach to organized error. Ergonomics, 38, 1708-1721.

Reason, J., 1997. Managing the risks of organisational accidents. Ashgate, Aldershot.

Reason, J., 2000. Human errors: models and management. British Journal of Management, $320,768-770$.

Roediger, H. L., 1980. Memory metaphors in cognitive Psychology. Memory and Cognition, $8,231-246$.

Salminen, S. \& Tallberg, T., 1996. Human errors in serious and fatal occupational accidents in Finland. Ergonomics, 39, 980-988.

Schanteau, J., 1992. Competence in experts: The role of tasks characteristics. Organisational Behavior and Human Decision Processes, 53, 252-266.

Schraagen, J. M. \& Schaafstal, A. M., 1996. Training of systematic diagnosis: A case study in electronics troubleshooting. Le Travail Humain, 59, 5-21.

Shank, R. \& Abelson, R., 1977. Scripts, plans, goals and understanding. Hillsdale, NJ, Erlbaum.

Simon, H. A., 1957. Models of Man. New York, Wiley.

Sperandio, J.-C., 1995. L'ergonomie cognitive: améliorer les aspects cognitifs du travail humain (Cognitive ergonomics: improving the cognitive aspects of work). Psychologie Française, 40, 3-11.

Van Elslande, P., 1992. Les erreurs d'interprétation en conduite automobile: mauvaise catégorisation ou activation erronée de schémas? (Interpretation errors in car driving: wrong categorisation or erroneous activation of schemas?) Intellectica, 15, 125-149.

Walker, N. \& Olson, J. R., 1988. Designing keybindings to be easy to learn and resistant to forgetting even when the set of commands is large. In Proceedings of SIGCHI conference on human factors in computing systems, Washington DC (pp. 201-206).

Woods, D. D., O’Brien, J. F. \& Hanes, L. F., 1987. In G. Salvendy (Ed.) Handbook on Human Factors, New York, John Wiley \& Sons (pp. 1724-1770). 


\section{ACKNOWLEDGEMENTS}

This paper was written at the University of Newcastle upon Tyne within the DIRC project (www.dirc.org.uk), a UK-based interdisciplinary research collaboration on the dependability of computer-based systems. The authors wish to thank David Greathead and Budi Arief (University of Newcastle upon Tyne, UK), Peter Popov (City University, UK), Michael Hildebrandt (University of York, UK), Mark Rouncefield (University of Lancaster, UK) and anonymous reviewers for useful comments. The authors are also grateful to EPSRC for funding this research and to ASCOMETAL for their key contribution to the study. 